\title{
Aberrant DNA hypomethylation of miR-196b contributes to migration and invasion of oral cancer
}

\author{
YU-YI HOU ${ }^{1,2}$, JYUN-JIE YOU ${ }^{3,4}$, CHENG-MEI YANG ${ }^{5,6}$, HUNG-WEI PAN ${ }^{4}$, \\ HUNG-CHIH CHEN ${ }^{5,6}$, JANG-HWA LEE ${ }^{7}$, YAOH-SHIANG LIN ${ }^{1}$, HUEI-HAN LIOU ${ }^{4}$, \\ PEI-FENG LIU ${ }^{4}$, CHAO-CHUAN CHI ${ }^{1}$, LUO-PING GER ${ }^{3,4}$ and KUO-WANG TSAI ${ }^{4}$ \\ ${ }^{1}$ Department of Otolaryngology, Kaohsiung Veterans General Hospital, Kaohsiung 813; \\ ${ }^{2}$ Department of Nursing, Yuh-Ing Junior College of Health Care and Management, Kaohsiung 807; \\ ${ }^{3}$ Institute of Biomedical Sciences, National Sun Yat-Sen University, Kaohsiung 80424; \\ Departments of ${ }^{4}$ Medical Education and Research, and ${ }^{5}$ Stomatology, Kaohsiung Veterans General Hospital, Kaohsiung 813; \\ ${ }^{6}$ Department of Dental Technology, Shu-Zen Junior College of Medicine and Management, Kaohsiung 821; \\ ${ }^{7}$ Department of Pathology and Laboratory Medicine, Kaohsiung Veterans General Hospital, Kaohsiung 813, Taiwan, R.O.C.
}

Received March 12, 2015; Accepted March 22, 2016

DOI: $10.3892 / \mathrm{ol} .2016 .4491$

\begin{abstract}
MicroRNAs (miRs) are a class of small endogenous non-coding RNAs of 21-24 nucleotides in length. Previous studies have indicated that miR-196b has either an oncogenic or tumor-suppressive function in various types of cancer. However, the biological role of miR-196b in oral squamous cell carcinoma (OSCC) remains unclear. In the present study, the expression levels of miR-196b were examined in oral cancer tissues and corresponding adjacent normal tissues from 69 OSCC patients using stem-loop reverse transcription-quantitative polymerase chain reaction. The results indicated that miR-196b was significantly overexpressed in OSCC tissues compared with the corresponding adjacent normal tissue samples (64 of 69, 92.7\%, $\mathrm{P}<0.001$ ). Analysis of the methylation status of the miR-196b gene indicated more frequent hypomethylation of the $\mathrm{CpG}$ islands located upstream of the miR-196b gene in the OSCC tissues than in the adjacent normal tissues (32 of 69, 46.3\%), and the methylation status of miR-196b correlated inversely with its expression levels. Furthermore, the unmethylated status of the miR-196b promoter correlated with poor disease-specific survival in OSCC patients $(\mathrm{P}=0.035)$. Functional analysis revealed that ectopic miR-196b expression promoted oral cancer cell migration and invasion abilities, and that silencing of miR-196b could abrogate in vitro migration and invasion of oral cancer cells. Collectively, the present findings indicate
\end{abstract}

Correspondence to: Dr Kuo-Wang Tsai or Professor Luo-Ping Ger, Department of Medical Education and Research, Kaohsiung Veterans General Hospital, 386 Ta-Chung 1st Road, Kaohsiung 813, Taiwan, R.O.C.

E-mail:kwtsai@vghks.gov.tw

E-mail: lpger@vghks.gov.tw

Key words: microRNA, DNA methylation, oral cancer, migration that the epigenetic regulation of miR-196b expression plays a crucial role in modulating cell migration and invasion during OSCC progression, and thus may serve as a potential prognosis marker or therapeutic target for OSCC.

\section{Introduction}

Oral cancer is one of the most common types of cancer worldwide, and includes malignancies of the oral cavity, lip, tongue, gums, retromolar region and oropharynx (1). Oral cancer is the sixth leading cause of cancer-associated mortality in men, with an estimated 263,900 novel cases and 128,000 associated mortalities annually (2). Oral squamous cell carcinoma (OSCC) is the most common type of oral cancer, and accounts for $>90 \%$ of all oral malignancies, thus being a major cause of cancer-associated morbidity and mortality worldwide (3). Metastasis is a major consequence of treatment failure, leading to a poor prognosis in OSCC patients (4). Therefore, studies on OSCC metastasis and proliferation are particularly crucial.

MicroRNAs (miRNAs or miRs) are a group of small, endogenous non-coding RNAs with single strands of 21-24 nucleotides, and play a crucial role in the regulation of eukaryotic gene expression by base pairing with their targeted messenger (m)RNAs at their 3'-untranslated regions (UTRs), which results in the cleavage or translational inhibition of the target mRNA $(5,6)$. In human cancer, miRNAs are involved in multiples biological processes, including cell growth, differentiation, apoptosis and regulation of the cell cycle $(5,6)$. In recent years, numerous studies have identified several dysfunctional miRNAs associated with the development and progression of OSCC, including miR-10b, miR-21, miR-31, miR-98, miR-101, miR-143, miR-184, miR-210, miR-221 and miR-222 (7-16). The miR-196 family of miRNAs appears to be expressed from intergenic regions in clusters of homeobox (HOX) genes, where several HOX genes are regulated by targeting their 3'-UTRs $(17,18)$. A previous study by the present authors revealed that miRNAs of the miR-196 family play a potential 
oncogenic role in gastric cancer, and their expression may be regulated through DNA methylation (19-21). Lim et al (22) reported that the expression of miR-196b positively correlated with HOXA10 expression and poor prognosis in gastric cancer. Furthermore, miR-196a directly targets annexin A1, thus inducing cell proliferation and anchorage-independent growth, and suppressing apoptosis, which suggests that miR-196a has oncogenic potential in esophageal cancer (23). Collectively, those studies revealed that miR-196b expression plays an oncogenic role in gastric and esophageal cancer. In contrast to the aforementioned results, other studies have reported that miR-196b plays a tumor-suppressive role in leukemia, as well as breast and cervical cancer (24-27). Although dysfunctional miR-196b has been reported to be involved in oral cancer metastasis $(13,28)$, its regulatory mechanism in OSCC remains unclear. The present study demonstrated that DNA hypomethylation led to miR-196b overexpression and facilitated OSCC cell migration and invasion.

\section{Materials and methods}

Patients and tissue samples. The protocol for the present study was independently reviewed and approved by the Institutional Review Board (IRB) of Kaohsiung Veterans General Hospital (KSVGH; IRB no. VGHKS14-CT6-18, Kaohsiung, Taiwan). A total of 69 paired tumor tissues and adjacent normal tissue samples were collected from patients with oral cancer at the Department of Otolaryngology of Kaohsiung Veterans General Hospital (Kaohsiung, Taiwan) between 2010 and 2012. The requirements for written informed consent from the subjects were waived by the IRB of KSVGH, since all the data and specimens had been previously collected and analyzed anonymously. Pathological tumor-node-metastasis classification was determined at the time of the initial resection of the tumor in accordance with the 2002 guidelines of the American Joint Committee on Cancer staging system (29). Fresh tissue samples included tumor tissues and corresponding adjacent normal tissues from 69 OSCC patients. Following surgery, samples were immediately placed in RNAlater ${ }^{\circledR}$ solution (Qiagen $\mathrm{GmbH}$, Hilden, Germany) and stored at room temperature overnight prior to be frozen at $-80^{\circ} \mathrm{C}$.

DNA and RNA extraction. Total RNA and DNA were extracted from tissues using TRIzol reagent (Invitrogen; Thermo Fisher Scientific, Inc., Waltham, MA, USA), according to the manufacturer's protocol. Briefly, tissue samples were homogenized in $1 \mathrm{ml}$ TRIzol and mixed with $0.2 \mathrm{ml}$ chloroform (Avantor Performance Materials, Center Valley, PA, USA) for extracting protein and DNA, while RNA was precipitated with $0.6 \mathrm{ml}$ isopropanol (Avantor Performance Materials). The remaining liquid was mixed with $0.5 \mathrm{ml}$ back extraction buffer (4 M guanidine thiocyanate, $50 \mathrm{mM}$ sodium citrate and $1 \mathrm{M}$ Tris; $\mathrm{pH}$ 8.0; Avantor Performance Materials), and DNA was precipitated with $0.4 \mathrm{ml}$ isopropanol. The concentration, purity and amount of total RNA and DNA were determined with a NanoDrop 1000 spectrophotometer (Nanodrop Technologies; Thermo Fisher Scientific, Inc.).

Stem-loop reverse-transcription-quantitative polymerase chain reaction $(R T-q P C R)$ of mature miRNAs. Total RNA
$(1 \mu \mathrm{g})$ was reverse transcribed using miR-specific stem-loop miR-196b-RT primer (Gemomics BioSci \& Tech, New Taipei, Taiwan) and SuperScript ${ }^{\circledR}$ III Reverse Transcriptase (Invitrogen; Thermo Fisher Scientific, Inc.), according to the manufacturer's protocol. The RT reaction included $1 \mu \mathrm{g}$ RNA, $1 \mathrm{X}$ buffer, $2.5 \mathrm{mM}$ dNTP and $0.5 \mathrm{mM}$ stem-loop miR-196b RT primer. The reaction was performed using the following incubation conditions with a PCR thermocycler (TPersonal 20 Thermal Cycler ; Biometra GmbH, Göttingen, Germany): $16^{\circ} \mathrm{C}$ for $30 \mathrm{~min}$, followed by 50 cycles of $20^{\circ} \mathrm{C}$ for $30 \mathrm{sec}, 42^{\circ} \mathrm{C}$ for $30 \mathrm{sec}$ and $50^{\circ} \mathrm{C}$ for $1 \mathrm{sec}$. The complementary DNA was used at a dilution of 1:20 in water in the subsequent qPCR, which was performed using a specific forward primer and a universal reverse primer, under the following conditions: Incubation at $94^{\circ} \mathrm{C}$ for $10 \mathrm{~min}$, followed by 40 cycles of $94^{\circ} \mathrm{C}$ for $15 \mathrm{sec}$ and $60^{\circ} \mathrm{C}$ for $30 \mathrm{sec}$. Gene expression was detected with SYBR Green I (Applied Biosystems; Thermo Fisher Scientific, Inc.). The expression levels of miRNAs were normalized to those of U6 ( $\triangle \mathrm{Cq}=\mathrm{miR}-196 \mathrm{~b} \mathrm{Cq}-\mathrm{U} 6 \mathrm{Cq})$ as described by Livak and Schmittgen (30). The individual primers were synthesized by Qiagen China Co.,Ltd. (Shanghai, China) used in the present study were as follows: miR-196b RT, foward 5'-CTCAACTGG TGTCGTGGAGTCGGCAATTCAGTTGAGCCCAACAA-3' and gene specific forward primer, 5'-CGGCGGTAGGTAGTT TCCTGTT-3'; universal/miR-196b reverse, 5'-CTGGTGTCG TGGAGTCGGCAATTC-3'; and U6 forward, 5'-CTCGCT TCGGCAGCACA-3' and reverse, 5'-AACGCTTCACGAATT TGCGT-3'.

Genomic DNA bisulfite conversion. Genomic DNA was extracted from oral tissue samples using TRIzol, and an aliquot $(2 \mu \mathrm{g})$ was subjected to bisulfite conversion using the EZ DNA Methylation-Gold ${ }^{\mathrm{TM}}$ kit (Zymo Research Corporation, Irvine, CA, USA). Bisulfite conversion was achieved by incubating the reaction at $98^{\circ} \mathrm{C}$ for $10 \mathrm{~min}, 64^{\circ} \mathrm{C}$ for $2.5 \mathrm{~h}$ and $4^{\circ} \mathrm{C}$ for $\leq 20 \mathrm{~h}$ in a PCR thermocycler (Biometra $\left.\mathrm{GmbH}\right)$.

Combined bisulfite restriction analysis (COBRA) and bisulfite sequencing analysis. Bisulfite-converted genomic DNA was used for methylation analysis of $\mathrm{CpG}$ islands with specific methylation primers. The PCR conditions were as follows: $94^{\circ} \mathrm{C}$ for $10 \mathrm{~min}$, followed by 40 cycles of $94^{\circ} \mathrm{C}$ for $30 \mathrm{sec}$, $60^{\circ} \mathrm{C}$ for $3 \mathrm{sec}$ and $72^{\circ} \mathrm{C}$ for $40 \mathrm{sec}$, with a final extension at $72^{\circ} \mathrm{C}$ for $10 \mathrm{~min}$. A PCR thermocycler (Biometra $\mathrm{GmbH}$ ) and Hot Start Taq DNA polymerase (Qiagen $\mathrm{GmbH}$ ) were used for the reaction. The methylation status of the genomic DNA of individual samples was examined by TaqI digestion (New England BioLabs, Inc., Ipswich, MA, USA). The digested PCR fragments were then separated on a $2 \%$ agarose gel (Invitrogen; Thermo Fisher Scientific, Inc.) immersed in $1 \mathrm{X}$ Tris-acetate-ethylenediaminetetraacetic acid buffer (Omics Bio, Taipei, Taiwan) using Mupid-2plus DNA Gel Electrophoresis system (Advance Co., Ltd., Tokyo, Japan). Following ethidium bromide (MDBio, INc., Taipei, Taiwan) staining, the gels were visualized and anlyzed by a gel documentation system (Uvitec Cambridge, Cambridge, UK) In addition, the PCR products were cloned into the pGEM $^{\circledR}$-T vector (Promega Corporation, Madison, WI, USA), and several clones were randomly selected for sequencing using a T7 primer (5'-TAA TACGACTCACTATAGGG-3') by Qiagen China Co., Ltd.. 
The individual primers used in the COBRA assay were as follows: miR-196b mF (forward primer), 5'-GAGAGAAAG GTGGATTTTAATAATAGGA-3' and $\mathrm{mR}$ (reverse primer), 5'-AACCTATAACTTCCCCTTCCTTAAC-3'.

Establishment of stable clones. Human oral cancer SAS and Cal-27 cell lines were kindly provided by Dr Michael Hsiao (Genomics Research Center, Academia Sinica, Taipei, Taiwan). The oral cancer cell lines, SASA and CAL27, were cultured in Dulbecco's modified Eagle's medium (Biological Industries Israel Beit-Haemek Ltd., Kibbutz Beit-Haemek, Israel) supplemented with $10 \%$ fetal bovine serum (GE Healthcare Life Sciences, Logan, UT, USA) and 1\% penicillin/ streptomycin (Sigma-Aldrich, St. Louis, MO, USA). Stable or transient SAS and CAL-27 cell cultures expressing miR-196b were generated by transfecting SAS and CAL-27 oral cancer cells with the pLKO.1 vector (Addgene, Inc., Cambridge, MA, USA) or with pLKO.1-miRNA-196b plasmid using Lipofectamine $^{\circledR} 2000$ (Invitrogen; Thermo Fisher Scientific, Inc.). At $24 \mathrm{~h}$ post-transfection, stable cells expressing miR-196b were generated using puromycin (Sigma-Aldrich) selection for 14 days. The levels of miR-196b expression were measured by RT-qPCR as described previously in the 'Stem-loop reverse-transcription-quantitative polymerase chain reaction' section.

Antagomir assay. The sequence complementary to miR-196b, 5'-CCCAACAACAGGAAACUACCUA-3', and the negative control (NC) sequence, 5'-GUGUAACACGUCUAUACG CCCA-3', referred to as anti-miR-196b and anti-miR-NC, respectively, were synthesized with 2'-O-methyl oligo modified bases exhibiting phosphorothioate on the first two and final four bases and a 3-cholesterol modification, which was added through a hydroxyprolinol linkage (Dharmacon; GE Healthcare Life Sciences, Chalfont, UK). Transfection of these antagomirs was performed using Lipofectamine ${ }^{\circledR}$ RNAiMAX (Invitrogen; Thermo Fisher Scientific, Inc.), according to the manufacturer's protocol. Cells were incubated with $100 \mathrm{nM}$ anti-miR-196b for 2 days to suppress miR-196b expression.

Cell proliferation, migration and invasion assays. For the cell proliferation assay, living cells $\left(3 \times 10^{3}\right)$ were plated onto 96-well plates, and cell growth was determined 0-4 days later using WST-1 cell proliferation reagent (Roche Diagnostics, Basel, Switzerland). The absorbance value at $450 \mathrm{~nm}$ of each well was measured using a plate reader (Multiskan FC Microplate Photometer; Invitrogen ${ }^{\mathrm{TM}}$, Thermo Fisher Scientific, Inc.). Cells were also tested for their invasion ability in vitro using Transwell chambers (BD Biosciences, Franklin Lakes, NJ, USA). The lower side of the polycarbonate membranes (containing $8-\mu \mathrm{m}$ pores) of the Transwell chamber was coated with Matrigel ( 1 or $0.2 \mu \mathrm{g} / \mathrm{ml} /$ well; BD Biosciences). Cells $\left(5 \times 10^{4}\right)$ were then added onto the Matrigel layer in each well. Following incubation for $48 \mathrm{~h}$ at $37^{\circ} \mathrm{C}$, the cells that had migrated through the Matrigel layer were visualized upon fixation with formaldehyde (BS Chemical, Kretinga, Lithuania) and staining with crystal violet (EMD Millipore, Billerica, MA, USA). The level of invasion was determined using a microscope (CKX41; Olympus Corporation, Tokyo, Japan). For the migration assay, cells $\left(1.5 \times 10^{6}\right)$ were plated
Table I. Clinicopathological data of patients with oral squamous cell carcinoma.

\begin{tabular}{lc} 
Variable & No. of patients \\
\hline Age, years & \\
$\leq 50$ & $18(26.1)$ \\
$>50$ & $51(73.9)$ \\
Cell differentiation & \\
Well & $11(15.9)$ \\
Moderately & $52(75.4)$ \\
Poorly & $6(8.7)$ \\
AJCC pathological stage & \\
I & $11(15.9)$ \\
II & $21(30.4)$ \\
III & $4(5.8)$ \\
IV & $33(47.8)$ \\
Tumor classification & \\
T1 & $11(15.9)$ \\
T2 & $26(37.7)$ \\
T3 & $6(8.7)$ \\
T4 & $26(37.7)$ \\
Node classification & \\
N0 & \\
N1 & $49(71.0)$ \\
N2 & $5(7.2)$ \\
\hline
\end{tabular}

AJCC, American Joint Committee on Cancer.

onto 6-well plates. A straight line was scratched into the cell monolayer in the middle of the well using a 200-ml pipette tip. Culture medium containing $10 \%$ fetal bovine serum was replaced with a serum-deprived culture medium, and the cells were then incubated at $37^{\circ} \mathrm{C}$. Wound closure was monitored and photographed at 0,6 and $12 \mathrm{~h}$ under a microscope.

Western blotting. Protien was was extracted from $3 \times 10^{6}$ cells using $200 \mu \mathrm{l}$ radioimmunoprecipitation assay buffer. A total of $30 \mu \mathrm{g}$ of protein lysate was electrophoresed on $10 \%$ sodium dodecyl sulfate polyacrylamide gels (Sigma-Aldrich) and transferred onto polyvinylidene difluoride membranes (EMD Millipore). The membranes were blocked with blocking buffer [50 mM Tris- $\mathrm{HCl}$ (pH 7.6), $150 \mathrm{mM} \mathrm{NaCl}, 0.1 \%$ Tween 20, 5\% non-fat dry milk, $0.05 \%$ sodium azide) for $1 \mathrm{~h}$ at room temperature. The membranes were incubated with the following primary antibodies overnight at $4^{\circ} \mathrm{C}$ : Polyclonal rabbit anti-fibronectin (dilution, 1:1,000; catalog no., GTX112794; GeneTex, Inc., Irvine, CA, USA); monoclonal rabbit anti-EpCAM (dilution, 1:2,000; catalog no., GTX61060; GeneTex, Inc.); polyclonal rabbit anti-vimentin (dilution, 1:2,000; catalog no., GTX100619; GeneTex, Inc.); polyclonal rabbit anti-Twist1/2 (dilution, 1:2,000; catalog no., GTX127310; GeneTex, Inc.); monoclonal rabbit anti-E-cadherin (dilution, 1:2,000; catalog no., GTX61329; GeneTex, Inc.); and monoclonal mouse anti-actin (dilution, 1:5,000, catalog no., MAB1501). Following washing three time for $10 \mathrm{~min} / \mathrm{time}$ 
A

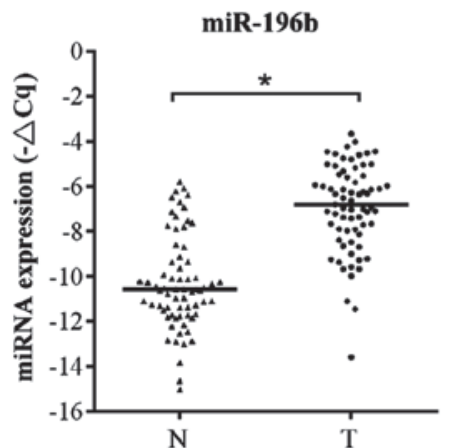

D

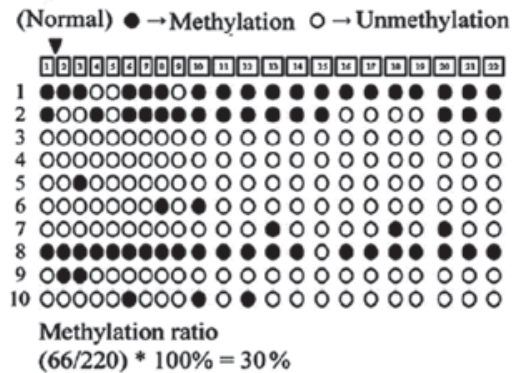

B

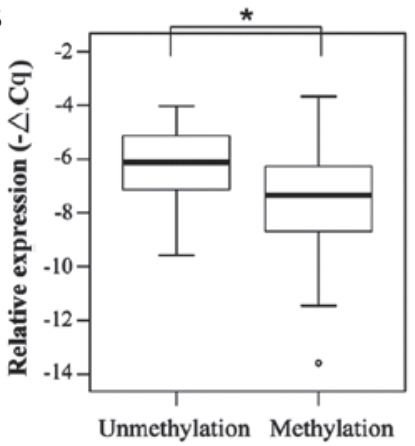

$\mathbf{C}$

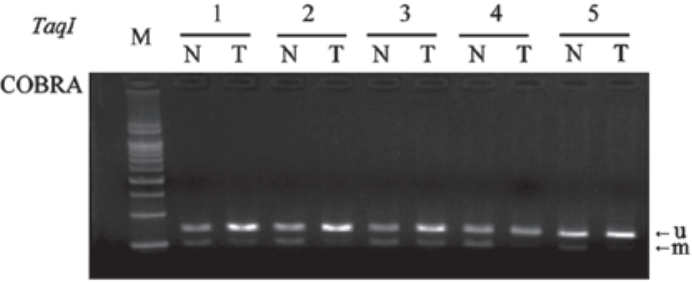

$\mathbf{E}$

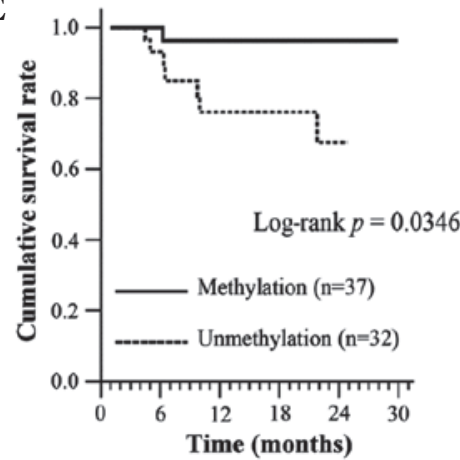

Figure 1. Epigenetic-regulated overexpression of miR-196b in 69 OSCC patients. (A) The expression levels of miR-196b in normal and tumor tissue pairs from 69 OSCC patients were examined using stem-loop reverse transcription-quantitative PCR. Gene expression was calculated relative to that of an internal control $(-\Delta \mathrm{Cq})$. The expression levels of miR-196b were normalized to U6 expression ("P<0.001). (B) Low expression levels of miR-196b were significantly associated with DNA hypermethylation in primary OSCC tumors $(\mathrm{P}=0.0009)$. (C) The methylation status of the $\mathrm{CpG}$ islands in the miR-196b gene was examined in 69 OSCC patients by combined bisulfite restriction analysis. Unmethylated (u) and methylated (m) alleles are presented. Representative OSCC cases (1-5) are shown. (D) The methylation status of the CpG islands of the miR-196b promoter region in one OSCC case (case 5) was analyzed by sequencing the PCR product of bisulfite-treated genomic DNA. A total of $22 \mathrm{CpG}$ dinucleotides were included within the PCR product. Open and filled circles represent unmethylated and methylated CpG sites, respectively. (E) DNA unmethylation of the miR-196b promoter in OSCC patients was significantly associated with poor disease-specific survival. miR/miRNA, microRNA; M, marker; $\mathrm{N}$, adjacent normal tissue; T, tumor; COBRA, combined bisulfite restriction analysis; OSCC, oral squamous cell carcinoma; PCR, polymerase chain reaction.

with Tris-buffered saline with Tween 20, the membranes were incubated with the following horseradish peroxidase-conjugated secondary antibodies for 1 hour at room temperature: Goat anti-mouse immunoglobulin (Ig)G (dilution, 1:20,000; catalog no., sc-2005; Santa Cruz Biotechnology, Inc., Dallas, TX, USA) and goat anti-rabbit IgG (dilution, 1:20,000; catalog no., sc-2004; Santa Cruz Biotechnology, Inc.). The target bands were visulized using WesternBright enhanced chemiluminescence reagent (Advansta, Inc., Menlo Park, CA, USA) and the results of the immunoreactions were analyzed with a BioSpectrum ${ }^{\circledR} 500$ Imaging System (Ultra-Violet Products Ltd., Cambridge, UK). The bands corresponding to individual genes were analyzed using ImageJ (imagej.nih.gov/ij/index. $\mathrm{html}$ ) and the expression levels of these genes were normalized to those of actin.

Statistical analysis. The expression levels of miR-196b in all of the oral tissues were determined using stem-loop RT-qPCR. All reactions were performed in triplicate, and data were analyzed using the paired $t$ test or Student's $t$ test. The correlation between various clinicopathological characteristics and miR-196b expression levels (low vs. high) or methylation status (no vs. yes) was evaluated using the $\chi^{2}$ test or Fisher's exact test. Cumulative survival curves were estimated using the Kaplan-Meier method, and comparisons between the survival curves were performed by using the log-rank test. $\mathrm{P}<0.05$ was considered to indicate a statistically significant difference.

\section{Results}

DNA hypomethylation results in miR-196b overexpression in human OSCC. To investigate the biological role of miR-196b in OSCC, the expression levels in OSCC tissues and adjacent normal tissues were examined by stem-loop RT-qPCR. As represented in Fig. 1A, the expression levels of miR-196b were significantly upregulated in OSCC tissues, compared with the corresponding adjacent normal tissues (64 of 69, 92.7\%, $\mathrm{P}<0.001)$. In addition, the expression levels of miR-196b were significantly increased in tissues with DNA hypomethylation, compared with those with DNA hypermethylation in OSCC tissues (Fig. 1B; $\mathrm{P}=0.009$ ). A previous study by the present authors demonstrated that DNA hypomethylation could lead to miR-196b overexpression in gastric cancer (19). Therefore, the present study examined whether the DNA methylation status of CpG islands contributed to miR-196b overexpression in OSCC. Using COBRA, the methylation status of the miR-196b promoter region was assayed in OSCC samples and corresponding adjacent normal samples from 69 OSCC patients. DNA hypomethylation was more frequently observed in oral cancer tissues than in adjacent normal tissues (32 of 69, 46.3\%; Fig. 1C). The methylation status of individual $\mathrm{CpG}$ dinucleotides of the miR-196b promoter region was verified in selected patients using a bisulfate sequencing approach. Consistent with the COBRA results, the densities of methylated $\mathrm{CpG}$ dinucleotides were higher in normal tissues (methylation 
Table II. Association between the expression levels of miR-196b and the clinicopathological data of patients with oral squamous cell carcinoma.

$\operatorname{miR}-196 b(n=69)$

\begin{tabular}{|c|c|c|c|c|}
\hline \multirow[b]{2}{*}{ Variable } & \multicolumn{2}{|c|}{ No. of patients (\%) } & \multirow[b]{2}{*}{$\chi^{2}$} & \multirow[b]{2}{*}{ P-value ${ }^{a}$} \\
\hline & Low $(n=35)$ & $\operatorname{High}(\mathrm{n}=34)$ & & \\
\hline Gender & & & 0.633 & $0.477^{\mathrm{b}}$ \\
\hline Female & $3(37.5)$ & $5(62.5)$ & & \\
\hline Male & $32(52.5)$ & $29(47.5)$ & & \\
\hline Age, years & & & 4.503 & 0.034 \\
\hline$\leq 50$ & $13(72.2)$ & $5(27.8)$ & & \\
\hline$>50$ & $22(43.1)$ & $29(56.9)$ & & \\
\hline Cancer location & & & 2.280 & 0.320 \\
\hline Buccal & $14(53.8)$ & $12(46.2)$ & & \\
\hline Tongue & $8(66.7)$ & $4(33.3)$ & & \\
\hline Other oral mucosal sites & $13(41.9)$ & $18(58.1)$ & & \\
\hline Cell differentiation & & & 2.880 & 0.090 \\
\hline Well & $3(27.3)$ & $8(72.7)$ & & \\
\hline Moderate, poor & $32(55.2)$ & $26(44.8)$ & & \\
\hline AJCC pathological stage & & & 0.729 & 0.393 \\
\hline I, II & $18(56.3)$ & $14(43.8)$ & & \\
\hline III, IV & $17(45.9)$ & $20(54.1)$ & & \\
\hline Tumor classification & & & 0.354 & 0.552 \\
\hline $\mathrm{T} 1, \mathrm{~T} 2$ & $20(54.1)$ & $17(45.9)$ & & \\
\hline $\mathrm{T} 3, \mathrm{~T} 4$ & $15(46.9)$ & $17(53.1)$ & & \\
\hline Node classification & & & 0.969 & 0.325 \\
\hline No & $23(46.9)$ & $26(53.1)$ & & \\
\hline $\mathrm{N} 1, \mathrm{~N} 2$ & $12(60.0)$ & $8(40.0)$ & & \\
\hline
\end{tabular}

${ }^{\text {aP }}$-value was estimated by $\chi^{2}$ test. ${ }^{\text {b}} \mathrm{P}$-value was estimated by Fisher's exact test. miR, microRNA; AJCC, American Joint Committee on Cancer.

rate, $30 \%$ ) than in tumor tissues (methylation rate, $0 \%$; Fig. 1D). The data also indicated that CpG-rich regions of miR-196b were unmethylated in the oral cell lines SAS and CAL-27 (data not shown). These results indicated that abnormal DNA hypomethylation resulted in miR-196b overexpression in OSCC. The clinicopathological characteristics of the 69 independent OSCC patients are summarized in Table I. The data indicated that the expression levels and methylation status of miR-196b were not associated with any clinicopathological features (Tables II and III). Notably, the disease-specific survival (DSS) curves of patients with miR-196b promoters exhibiting unmethylation status were significantly lower than those displaying methylation status ( $\mathrm{P}=0.035$; Fig. 1E).

miR-196b involvement in the modulation of the migration and invasion abilities of oral cancer cells. Since miR-196b has been demonstrated to be able to act as an oncogene or as a tumor suppressor in various types of human cancer $(20,26)$, stable SAS and CAL-27 clones overexpressing miRNA-196b were established in the present study by transfecting SAS and CAL-27 cells with a precursor-miR-196b construct. As represented in Fig. 2A, miR-196b was significantly overexpressed in the two stable cell lines overexpressing miR-196b $(\mathrm{P}=0.37)$. The effect of miR-196b on the proliferation, migration and invasion abilities of SAS and CAL-27 cells was subsequently investigated. Ectopic overexpression of miR-196b did not induce a significant proliferation ability in these two cell lines (Fig. 2B). By contrast, the wound-healing assay indicated that the overexpression of miR-196b could significantly promote SAS and CAL-27 migration $(\mathrm{P}<0.01$; Fig. 2C). Furthermore, the invasion ability significantly increased in miR-196b-expressing SAS and CAL-27 cells (SAS cells, $\mathrm{P}=0.003$; CAL-27 cells, $\mathrm{P}=0.001$; Fig. 2D). Endogenous expression of miR-196b was knocked down in the SAS and CAL-27 cells by transfecting the cells with anti-miR-NC or anti-miR-196b. As indicated in Fig. 3, knockdown of endogenous miR-196b significantly inhibited the cell migration and invasion abilities of SAS and CAL-27 cells ( $\mathrm{P}<0.01$; Fig. $3 \mathrm{~A}$ and $\mathrm{B})$.

Since the epithelial-mesenchymal transition (EMT) is a crucial process in promoting cancer cell metastasis, the present study examined whether miR-196b could induce EMT in SAS and CAL-27 cells. As presented in Fig. 3C, the protein expression of endogenous fibronectin and was clearly decreased in SAS cells in which miR-196b was downregulated. However, 
Table III. Association between the DNA methylation status of miR-196b and the clinicopathological data of patients with oral squamous cell carcinoma.

\begin{tabular}{|c|c|c|c|c|}
\hline \multirow[b]{3}{*}{ Variables } & \multicolumn{4}{|c|}{ TaqI-DNA methylation $(\mathrm{n}=69)$} \\
\hline & \multicolumn{2}{|c|}{ No. of patients (\%) } & \multirow[b]{2}{*}{$\chi^{2}$} & \multirow[b]{2}{*}{ P-value ${ }^{a}$} \\
\hline & Unmethylation (n=32) & Methylation (n=37) & & \\
\hline Gender & & & 1.633 & $0.270^{\mathrm{b}}$ \\
\hline Female & $2(25.0)$ & $6(75.0)$ & & \\
\hline Male & $30(49.2)$ & $31(50.8)$ & & \\
\hline Age, years & & & 0.129 & 0.720 \\
\hline$\leq 50$ & $9(50.0)$ & $9(50.0)$ & & \\
\hline$>50$ & $23(45.1)$ & $28(54.9)$ & & \\
\hline Cancer location & & & 3.256 & 0.196 \\
\hline Buccal & $9(34.6)$ & $17(65.4)$ & & \\
\hline Tongue & $5(41.7)$ & $7(58.3)$ & & \\
\hline Other oral mucosal sites & $18(58.1)$ & $13(41.9)$ & & \\
\hline Cell differentiation & & & 0.528 & 0.468 \\
\hline Well & $4(36.4)$ & $7(63.6)$ & & \\
\hline Moderate, poor & $28(48.3)$ & $30(51.7)$ & & \\
\hline AJCC pathological stage & & & 1.891 & 0.169 \\
\hline I, II & $12(37.5)$ & $20(62.5)$ & & \\
\hline III, IV & $20(54.1)$ & $17(45.9)$ & & \\
\hline Tumor classification & & & 1.093 & 0.296 \\
\hline $\mathrm{T} 1, \mathrm{~T} 2$ & $15(40.5)$ & $22(59.5)$ & & \\
\hline $\mathrm{T} 3, \mathrm{~T} 4$ & $17(53.1)$ & $15(46.9)$ & & \\
\hline Node classification & & & 0.842 & 0.359 \\
\hline No & $21(42.9)$ & $28(57.1)$ & & \\
\hline $\mathrm{N} 1, \mathrm{~N} 2$ & $11(55.0)$ & $9(45.0)$ & & \\
\hline
\end{tabular}

${ }^{\text {aP }}$-value was estimated by $\chi^{2}$ test. ${ }^{\text {b }}$-value was estimated by Fisher's exact test. miR, microRNA; AJCC, American Joint Committee on Cancer.

the expression levels of the other EMT markers were not clearly altered in SAS cells with miR-196b knockdown.

In summary, DNA hypomethylation resulted in overexpression of oncogenic miR-196b in OSCC tissues, compared with corresponding adjacent normal tissues. Furthermore, DNA hypomethylation may serve as an adverse prognostic marker for OSCC.

\section{Discussion}

The expression pattern and functional role of miR-196b in various types of cancer remain controversial $(19,22-27)$. Previous studies have suggested that miR-196b could function as an oncogene or as a tumor suppressor $(19,22-27)$. In the present study, miR-196b was demonstrated to be overexpressed in oral cancer and to perform an oncogenic role in regulating OCSS cell migration and invasion abilities. In addition, the present study is the first to report that DNA hypomethylation contributes to miR-196b overexpression in OSCC. Similar to the results of a previous study by the present authors (19), the results of the present study revealed that miR-196b was upregulated in gastric cancer tissue samples with a hypomethylated promoter region. A high frequency of miR-196b overexpression was observed in OSCC patients (64 of 69, 92.7\%), while hypomethylated promoter regions were observed in $46.4 \%$ of the patients (32 of 69). Although DNA methylation is a critical factor in regulating $\mathrm{miR}-196 \mathrm{~b}$ expression, the regulation of miR-196b expression could also be modulated by other transcription regulatory factors, including v-Ets erythroblastosis virus E26 oncogene homolog 2, mixed-lineage leukemia and growth factor independent 1 (20,31,32).

Using a microarray approach, Lu et al (13) identified several differences in miRNA expression between an oral cancer cell line and normal oral keratinocytes, including increased miR-196b expression in oral cancer cells. Previous studies have indicated that overexpression of miR-196b is associated with the biological process of the cell cycle in glioblastomas (33), and observed decreased cell viability, proliferation and invasion in cervical cancer (26). In the present study, knockdown of miR-196b reduced cell migration and invasion, whereas overexpression of miR-196b could promote cell migration and invasion, but not proliferation. The detailed mechanism of miR-196b involved in regulating OSCC migration ability has not been thoroughly investigated to date. Therefore, identifying 
A

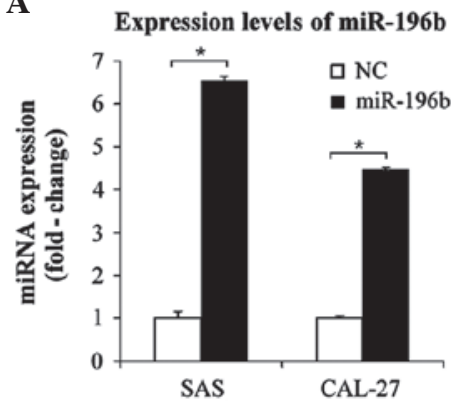

B

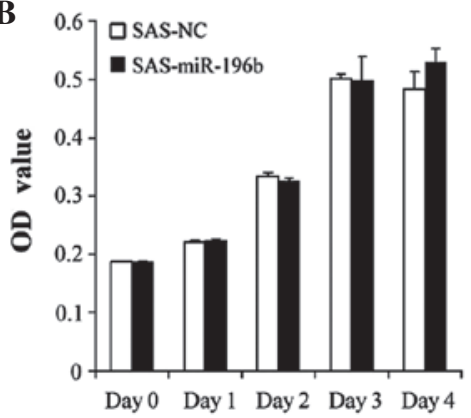

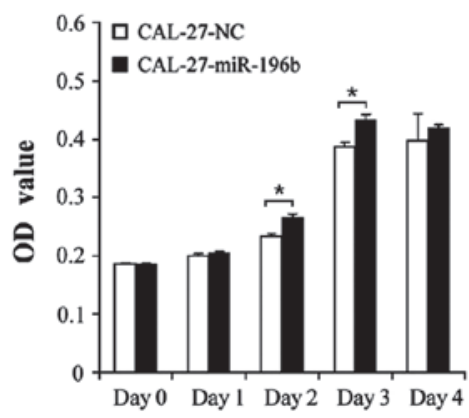

C
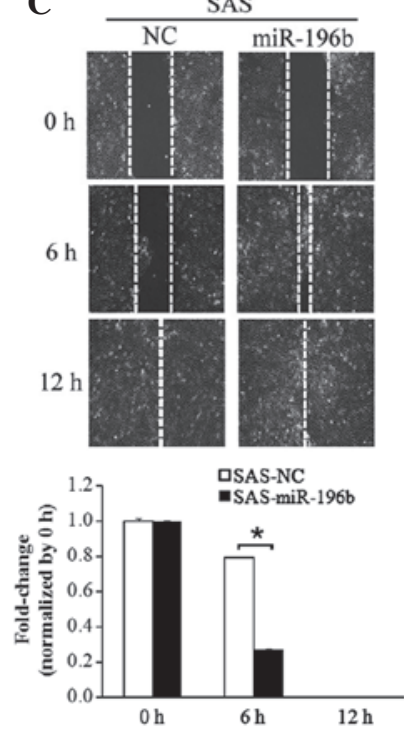
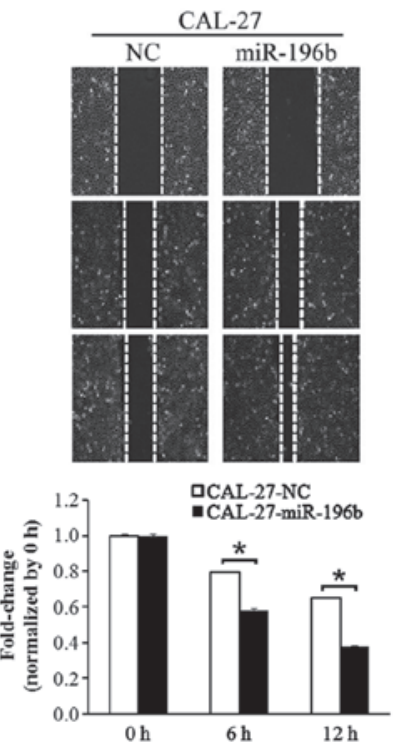

D

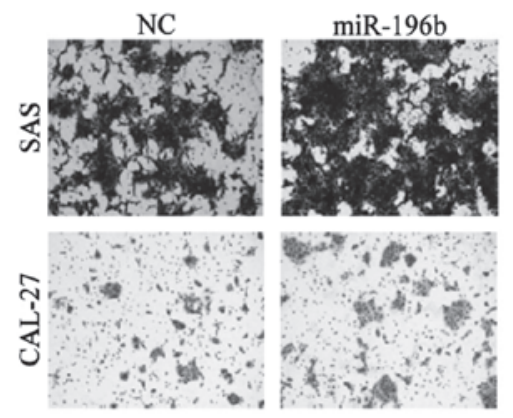

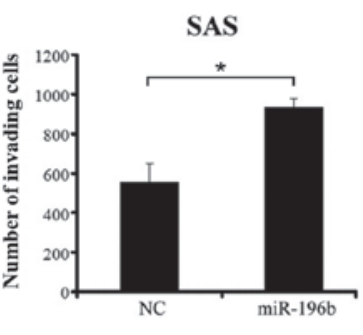

CAL-27

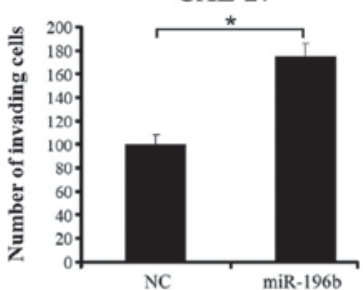

Figure 2. Overexpression of miR-196b promoted oral cancer cell migration and invasion abilities. (A) The expression levels of miR-196b were examined in stable SAS and CAL-27 cells expressing miR-196b by stem-loop reverse transcription-quantitative polymerase chain reaction. (B) The effect of miR-196b overexpression on SAS and CAL-27 cell growth was examined. Cell growth was assessed using the WST-1 cell proliferation reagent at days $0,1,2,3$ and 4. (C) The effect of miR-196b overexpression on SAS and CAL-27 cell migration ability was assessed using a wound-healing assay at 0, 6 and 12 h. Migration ability was quantified from three independent visible fields (magnification, x100). (D) The effect of miR-196b overexpression on SAS and CAL-27 cell invasion was examined using an invasion assay with Matrigel concentrations of 1 and $0.2 \mu \mathrm{g} / \mu 1$, respectively. Invasion ability was quantified by counting the number of invading cells per visible field (magnification, $\mathrm{x} 100)$. Data are presented as the mean \pm standard deviation of three independent experiments $\left({ }^{*} \mathrm{P}<0.05\right)$. miR/ miRNA, microRNA; OD, optical density; NC, negative control.

target genes of miR-196b is essential. Previous studies have identified various mRNA targets of miR-196b, including breakpoint cluster region-Abelson murine leukemia viral oncogene homolog 1, HOXA9, c-Myc, B-cell lymphoma 2, HOXB7, HOXA9, Meis HOX 1, Fas and HOXC8 (26,27,34-36). Combining a bioinformatic prediction tool with a microarray approach, 15 putative targets of miR-196b were identified in OSCC in the present study, including actin-related protein 10 homolog (Saccharomyces cerevisiae), doublecortin domaincontaining protein 2 (DCDC2), disrupted in renal carcinoma 2, epidermal growth factor receptor pathway substrate 15, gigaxonin, inhibitor of growth family, member 5 (ING5), kelch-like family member 23, ligand-dependent corepressor (LCOR), ovarian tumor domain-containing protein 6B, Parkin RBR E3 ubiquitin protein ligase co-regulated like, polymerase (RNA) III (DNA directed) polypeptide D, $44 \mathrm{kDa}$, ribonucleoprotein, phosphotyrosine binding-binding 2, sorting nexin 16, zinc finger DHHC-domain protein containing 21 and zinc finger, MYND-type containing 11 (ZMYND11; data not shown). Among them, DCDC2, ING5, LCOR and ZMYND11 have been reported to act as tumor suppressors in different types of human cancer (36-39). In previous studies, DCDC2 was reported to be hypermethylated in hepatocellular carcinoma (37), while ING5 could inhibit proliferation and induce apoptosis in tongue SCC (38), and LCOR could repress prostate cancer growth in vivo and in vitro, and was observed to be functionally inactivated by $\mathrm{Src}$, a proto-oncogene tyrosine-protein kinase (39). In addition, low expression levels of ZMYND11 in breast cancer patients were demonstrated to correlate with poor prognosis, and overexpression of ZMYND11 suppressed cancer cell growth in vitro and tumor formation in mice (40). At the time of writing the present manuscript, Lu et al (28) reported that miR-196 expression is involved in oral cancer metastasis via the non-metastatic cells 4, protein expressed in-c-Jun N-terminal kinase-tissue inhibitor of metalloproteinase (MP) 1-matrix MP signaling pathway. Additionally, assessing the levels of circulating miR-196s in plasma may serve as an early diagnostic biomarker for oral cancer (41).

Recently, correlations between miR-196b overexpression and poor prognosis have been identified in several types of cancer, including osteosarcoma, gastric cancer and glioblastoma $(22,33,38)$. Qi and Zhang (38) observed that high serum expression of miR-196a and/or miR-196b, and joint expression of miR-196a and miR-196b, are independent prognostic 
A

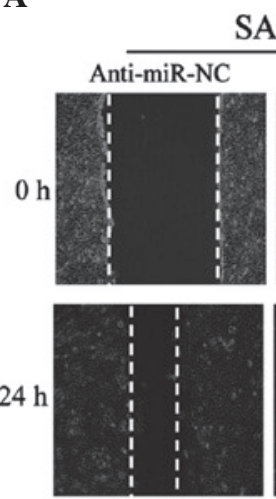

SAS

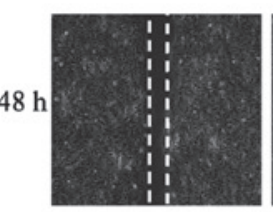

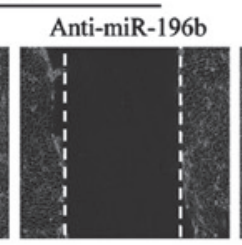
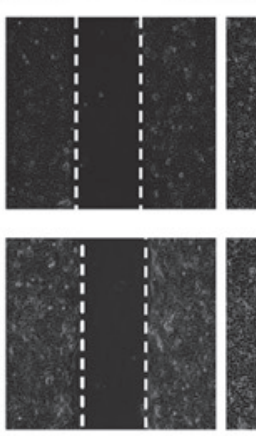
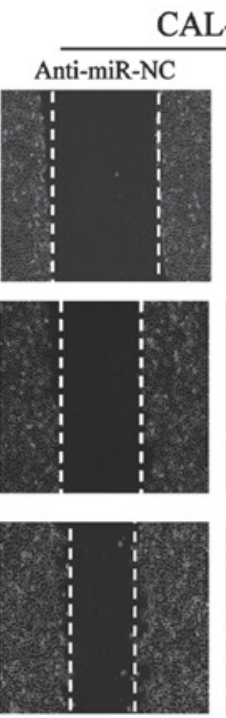

AL-27
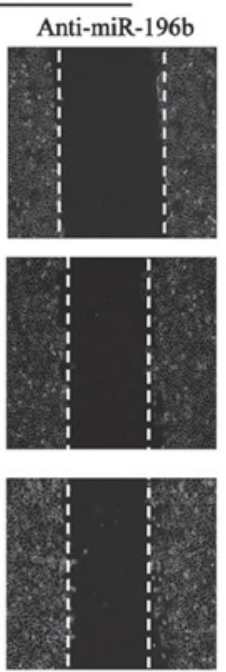

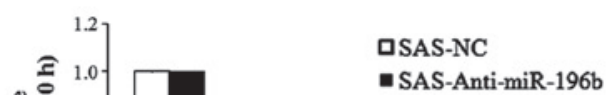

- SAS-Anti-miR-196b
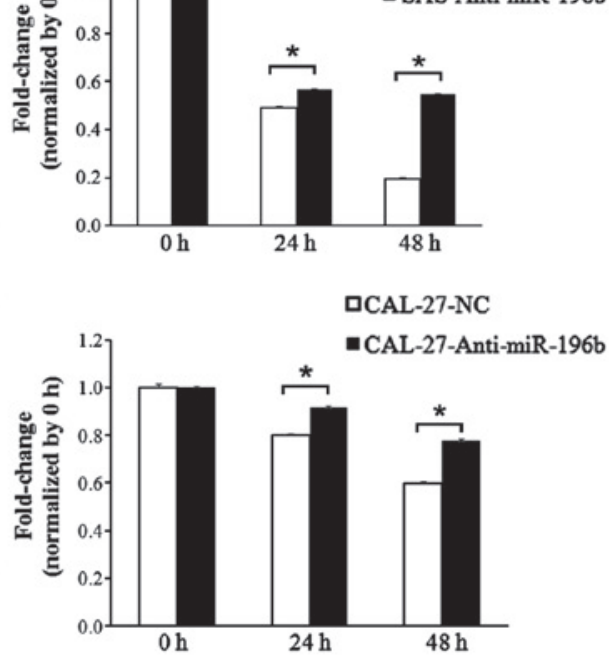

$\mathbf{B}$
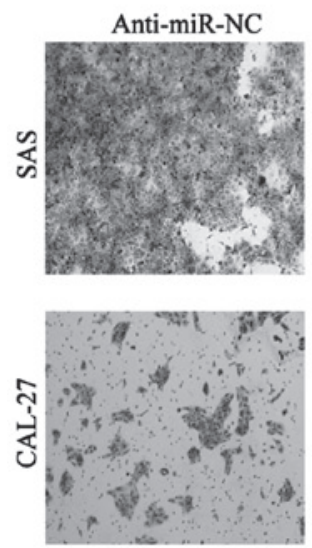

Anti-miR-NC
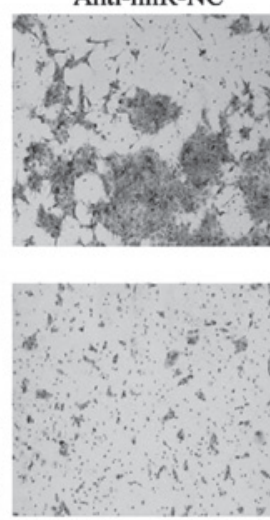

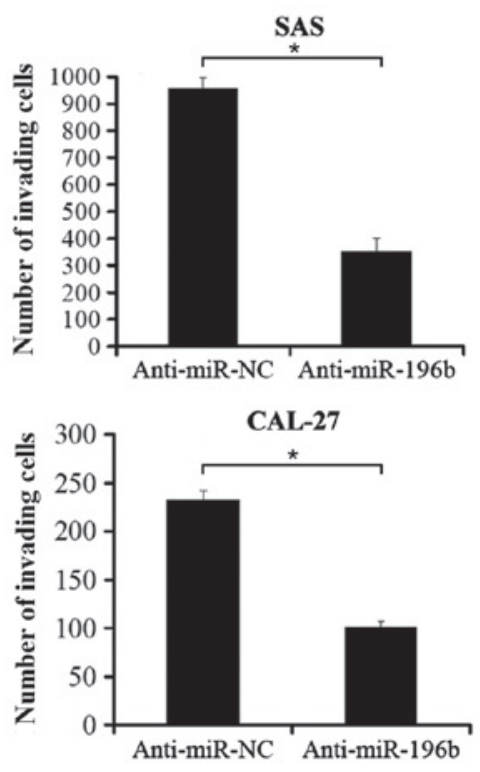

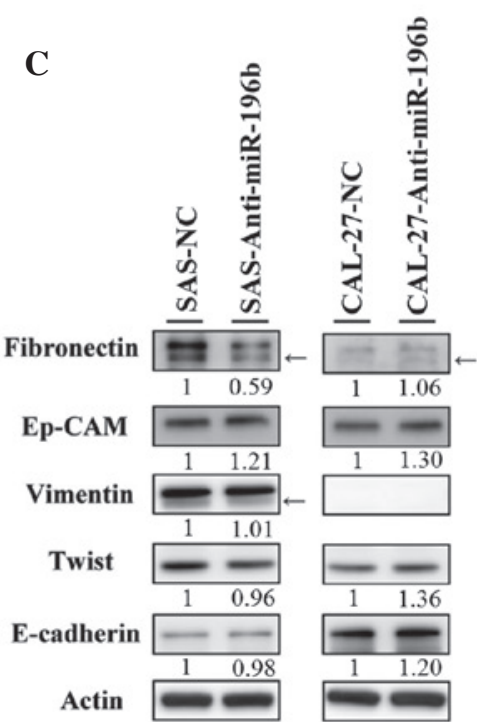

Figure 3. Knockdown of miR-196b inhibited oral cancer cell migration and invasion abilities. The expression of miR-196b was knocked down in SAS and CAL-27 cells by transient transfection with miR-196b antagomirs (anti-miR-196b). A scrambled oligonucleotide with a random sequence was used as a negative control. (A) The effect of miR-196b knockdown on SAS and CAL-27 cell migration was examined. Cancer cell migration ability was assessed using a wound-healing assay at 0,24 and 48 h. Migration ability was quantified from three independent visible fields (magnification, x100). (B) The effect of miR-196b knockdown on SAS and CAL-27 cell invasion was examined. Cancer cell invasion ability was assessed using an invasion assay, where Matrigel concentrations of 1 and $0.2 \mu \mathrm{g} / \mu 1$ were used for SAS and CAL-27 cells, respectively. Invasion ability was quantified by counting the number of invading cells per visible field (magnification, x100). Data are presented as the mean \pm standard deviation of three independent experiments ("P<0.05). (C) The expression of epithelial-mesenchymal transition markers, including fibronectin, epithelial cell adhesion molecule, vimentin, Twist and E-cadherin was examined by western blotting in SAS and CAL-27 cells with and without miR-196b knockdown. The bands corresponding to individual genes were analyzed using ImageJ. Arrows indicate non-specific bands. Actin was used as an internal control. miR, microRNA; NC, negative control; Ep-CAM, epithelial cell adhesion molecule.

factors for overall and disease-free survival of osteosarcoma patients. Lim et al (22) reported that overexpression of miR-196b and HOXA10 is a biomarker of poor prognosis in patients with gastric cancer. Ma et al (33) demonstrated that the upregulation of miR-196b is an independent biomarker of poor prognosis that promotes cellular proliferation in glioblastoma. Although Lu et al (28) reported that the expression levels of miR-196b were associated with clinical N stage. However, no clinicopathological features were significantly associated with miR-196b expression in oral cancer in the present study. Notably, the present data revealed that the unmethylation status of miR-196b in OSCC patients significantly correlated with poor survival. In conclusion, DNA hypomethylation contributed to regulating the expression of the oncogenic miR-196b, and the methylation status of miR-196b could be used as a prognostic biomarker for OSCC.

\section{Acknowledgments}

The present authors would like to acknowledge DrMichael Hsiao (Genomic Research Center, Academia Sinica, Taipei, Taiwan) for kindly providing the SAS and CAL-27 cell lines. The present study was supported by grants from the KSVGH (Kaohsiung, Taiwan; grants no. KSVGH 103-049 and KSVGH 103-106). 


\section{References}

1. Trotta BM, Pease CS, Rasamny JJ, Raghavan P and Mukherjee S: Oral cavity and oropharyngeal squamous cell cancer: Key imaging findings for staging and treatment planning. Radiographics 31: 339-354, 2011

2. Jemal A, Bray F, Center MM, Ferlay J, Ward E and Forman D: Global cancer statistics. CA Cancer J Clin 61: 69-90, 2011.

3. Nair S and Pillai MR: Human papillomavirus and disease mechanisms: Relevance to oral and cervical cancers. Oral Dis 11: 350-359, 2005

4. Kamangar F, Dores GM and Anderson WF: Patterns of cancer incidence, mortality, and prevalence across five continents: Defining priorities to reduce cancer disparities in different geographic regions of the world. J Clin Oncol 24: 2137-2150, 2006.

5. Esteller M: Non-coding RNAs in human disease. Nat Rev Genet 12: 861-874, 2011.

6. Wu HH,Lin WC and Tsai KW: Advances in molecular biomarkers for gastric cancer: miRNAs as emerging novel cancer markers Expert Rev Mol Med 16: e1, 2014

7. Avissar M, McClean MD, Kelsey KT and Marsit CJ: MicroRNA expression in head and neck cancer associates with alcohol consumption and survival. Carcinogenesis 30: 2059-2063, 2009.

8. Banerjee R, Mani RS, Russo N, Scanlon CS, Tsodikov A, Jing X, Cao Q, Palanisamy N, Metwally T, Inglehart RC, et al: The tumor suppressor gene rap1GAP is silenced by miR-101-mediated EZH2 overexpression in invasive squamous cell carcinoma. Oncogene 30: 4339-4349, 2011.

9. Gee HE, Camps C, Buffa FM, Patiar S, Winter SC, Betts G, Homer J, Corbridge R, Cox G, West CM, et al: Hsa-mir-210 is a marker of tumor hypoxia and a prognostic factor in head and neck cancer. Cancer 116: 2148-2158, 2010.

10. Hebert C, Norris K, Scheper MA, Nikitakis N and Sauk JJ: High mobility group A2 is a target for miRNA-98 in head and neck squamous cell carcinoma. Mol Cancer 6: 5, 2007.

11. Liu CJ, Tsai MM, Hung PS, Kao SY, Liu TY, Wu KJ, Chiou SH, Lin SC and Chang KW: miR-31 ablates expression of the HIF regulatory factor FIH to activate the HIF pathway in head and neck carcinoma. Cancer Res 70: 1635-1644, 2010.

12. Liu X, Jiang L, Wang A, Yu J, Shi F and Zhou X: MicroRNA-138 suppresses invasion and promotes apoptosis in head and neck squamous cell carcinoma cell lines. Cancer Lett 286: 217-222, 2009.

13. Lu YC, Chen YJ, Wang HM, Tsai CY, Chen WH, Huang YC, Fan KH, Tsai CN, Huang SF, Kang CJ, et al: Oncogenic function and early detection potential of miRNA-10b in oral cancer as identified by microRNA profiling. Cancer Prev Res (Phila) 5 : 665-674, 2012.

14. Peschiaroli A, Giacobbe A, Formosa A, Markert EK, Bongiorno-Borbone L, Levine AJ, Candi E, D'Alessandro A, Zolla L, Finazzi Agrò A and Melino G: miR-143 regulates hexokinase 2 expression in cancer cells. Oncogene 32: 797-802, 2013

15. Wong TS, Liu XB, Wong BY, Ng RW, Yuen AP and Wei WI: Mature miR-184 as potential oncogenic microRNA of squamous cell carcinoma of tongue. Clin Cancer Res 14: 2588-2592, 2008.

16. Yang CJ, Shen WG, Liu CJ, Chen YW, Lu HH, Tsai MM and Lin SC: miR-221 and miR-222 expression increased the growth and tumorigenesis of oral carcinoma cells. J Oral Pathol Med 40: 560-566, 2011

17. Yekta S, Shih IH and Bartel DP: MicroRNA-directed cleavage of HOXB8 mRNA. Science 304: 594-596, 2004.

18. Hornstein E, Mansfield JH, Yekta S, Hu JK, Harfe BD, McManus MT, Baskerville S, Bartel DP and Tabin CJ: The microRNA miR-196 acts upstream of Hoxb8 and Shh in limb development. Nature 438: 671-674, 2005.

19. Tsai KW, Hu LY, Wu CW, Li SC, Lai CH, Kao HW, Fang WL and Lin WC: Epigenetic regulation of miR-196b expression in gastric cancer. Genes Chromosomes Cancer 49: 969-980, 2010.

20. Liao YL, Hu LY, Tsai KW, Wu CW, Chan WC, Li SC, Lai CH, Ho MR, Fang WL, Huang KH and Lin WC: Transcriptional regulation of miR-196b by ETS2 in gastric cancer cells. Carcinogenesis 33: 760-769, 2012

21. Tsai KW, Liao YL, Wu CW, Hu LY, Li SC, Chan WC, Ho MR, Lai CH, Kao HW, Fang WL, et al: Aberrant expression of miR-196a in gastric cancers and correlation with recurrence. Genes Chromosomes Cancer 51: 394-401, 2012.

22. Lim JY, Yoon SO, Seol SY, Hong SW, Kim JW, Choi SH, Lee JS and Cho JY: Overexpression of miR-196b and HOXA10 characterize a poor-prognosis gastric cancer subtype. World J Gastroenterol 19: 7078-7088, 2013.
23. Luthra R, Singh RR, Luthra MG, Li YX, Hannah C, Romans AM, Barkoh BA, Chen SS, Ensor J, Maru DM, et al: MicroRNA-196a targets annexin A1: A microRNA-mediated mechanism of annexin A1 downregulation in cancers. Oncogene 27: 6667-6678, 2008.

24. Bhatia S, Kaul D and Varma N: Functional genomics of tumor suppressor miR-196b in T-cell acute lymphoblastic leukemia. Mol Cell Biochem 346: 103-116, 2011.

25. Coskun E, von der Heide EK, Schlee C, Kühnl A, Gökbuget N, Hoelzer D, Hofmann WK, Thiel E and Baldus CD: The role of microRNA-196a and microRNA-196b as ERG regulators in acute myeloid leukemia and acute T-lymphoblastic leukemia. Leuk Res 35: 208-213, 2011

26. How C, Hui AB, Alajez NM, Shi W, Boutros PC, Clarke BA, Yan R, Pintilie M, Fyles A, Hedley DW, et al: MicroRNA-196b regulates the homeobox B7-vascular endothelial growth factor axis in cervical cancer. PLoS One 8: e67846, 2013.

27. Li Y, Zhang M, Chen H, Dong Z, Ganapathy V, Thangaraju M and Huang S: Ratio of miR-196s to HOXC8 messenger RNA correlates with breast cancer cell migration and metastasis. Cancer Res 70: 7894-7904, 2010.

28. Lu YC, Chang JT, Liao CT, Kang CJ, Huang SF, Chen IH, Huang CC, Huang YC, Chen WH, Tsai CY, et al: OncomiR-196 promotes an invasive phenotype in oral cancer through the NME4-JNK-TIMP1-MMP signaling pathway. Mol Cancer 13: 218, 2014.

29. Greene FL, Page DL, Fleming ID, Fritz AG, Balch CM, Haller DG and Morrow M (eds): AJCC Cancer Staging Manual. 6th edition. Springer, New York, NY, 2002.

30. Livak KJ and Schmittgen TD: Analysis of relative gene expression data using real-time quantitative PCR and the 2(-Delta Delta C(T)) Method. Methods 25: 402-408, 2001

31. Popovic R, Riesbeck LE, Velu CS, Chaubey A, Zhang J, Achille NJ, Erfurth FE, Eaton K, Lu J, Grimes HL, et al: Regulation of mir-196b by MLL and its overexpression by MLL fusions contributes to immortalization. Blood 113: 3314-3322, 2009.

32. Velu CS, Baktula AM and Grimes HL: Gfi1 regulates miR-21 and miR-196b to control myelopoiesis. Blood 113: 4720-4728, 2009.

33. Ma R, Yan W, Zhang G, Lv H, Liu Z, Fang F, Zhang W, Zhang J, Tao T, You Y, et al: Upregulation of miR-196b confers a poor prognosis in glioblastoma patients via inducing a proliferative phenotype. PLoS One 7: e38096, 2012.

34. Liu Y, Zheng W, Song Y, Ma W and Yin H: Low expression of miR-196b enhances the expression of BCR-ABL1 and HOXA9 oncogenes in chronic myeloid leukemogenesis. PLoS One 8: e68442, 2013

35. Abe W, Nasu K, Nakada C, Kawano Y, Moriyama M and Narahara H: miR-196b targets c-myc and Bcl-2 expression, inhibits proliferation and induces apoptosis in endometriotic stromal cells. Hum Reprod 28: 750-761, 2013.

36. Li Z, Huang H, Chen P, He M, Li Y, Arnovitz S, Jiang X, He C, Hyjek E, Zhang J, et al: miR-196b directly targets both HOXA9/MEIS1 oncogenes and FAS tumour suppressor in MLL-rearranged leukaemia. Nat Commun 3: 688, 2012.

37. Inokawa $Y$, Nomoto $S$, Hishida $M$, Hayashi $M$, Kanda M, Nishikawa Y, Takeda S, Sugimoto H, Fujii T, Yamada S and Kodera Y: Detection of doublecortin domain-containing 2 (DCDC2), a new candidate tumor suppressor gene of hepatocellular carcinoma, by triple combination array analysis. J Exp Clin Cancer Res 32: 65, 2013.

38. Qi L and Zhang Y: Truncation of inhibitor of growth family protein 5 effectively induces senescence, but not apoptosis in human tongue squamous cell carcinoma cell line. Tumour Biol 35: 3139-3144, 2014.

39. Asim M, Hafeez BB, Siddiqui IA, Gerlach C, Patz M, Mukhtar H and Baniahmad A: Ligand-dependent corepressor acts as a novel androgen receptor corepressor, inhibits prostate cancer growth, and is functionally inactivated by the Src protein kinase. J Biol Chem 286: 37108-37117, 2011.

40. Wen H, Li Y, Xi Y, Jiang S, Stratton S, Peng D, Tanaka K, Ren Y, Xia Z, Wu J, et al: ZMYND11 links histone H3.3K36me3 to transcription elongation and tumour suppression. Nature 508: 263-268, 2014

41. Lu YC, Chang JT, Huang YC, Huang CC, Chen WH, Lee LY, Huang BS, Chen YJ, Li HF and Cheng AJ: Combined determination of circulating miR-196a and miR-196b levels produces high sensitivity and specificity for early detection of oral cancer. Clin Biochem 48: 115-121, 2015. 